DOI: $10.32481 / \mathrm{djph} .2021 .07 .015$

\title{
The Academy Welcomes its New Board Members
}

Daniel J. Meara, MD, DMD ${ }^{1}$ and S. John Swanson, MD²

1. Immediate Past President (2018-2021), Delaware Academy of Medicine/Delaware Public Health Association

2. President (2021-2023), Delaware Academy of Medicine/Delaware Public Health Association Every two years (in this case, three years due to the pandemic), new members are added to the Board of Directors, as other officers and Directors cycle off. This year, it was the duty of the immediate past president, Daniel J. Meara, MD, DMD (Figure 1), to oversee this process as Chair of Nominations.

Figure 1. Immediate Past President Daniel Meara discusses the process for adding new Board Members, while Secretary Lynn Jones looks on

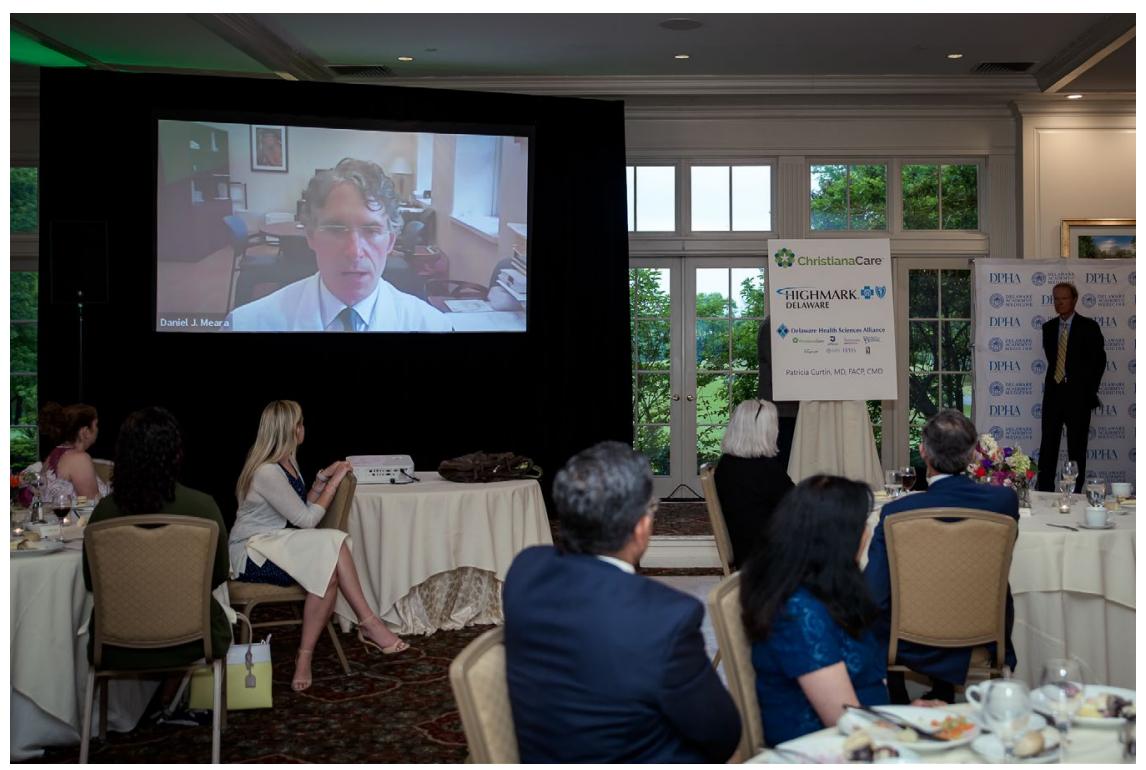

The process, as described in the Academy/DPHA by-laws, is that the immediate past president convenes a nominating committee of including two members of the Academy/DPHA who are members of the Board, and two members of the Academy/DPHA who are not members of the board.

This year, the nominations committee included the following individuals:

- Sarina Pasricha, MD

- Anand Panwalker, MD

- Lynn Jones, FACHE

- Professor Rita Landgraf

Through a series of brainstorming activities and discussions, a list of over twenty potential board members was developed, and from that list, six individuals were approached to become board members. 
That list of recommendations was submitted to and approved by the Academy/DPHA Board of Directors at our May 2021 meeting, and approved by the membership at the June 2021 Annual Meeting (figure 2).

Figure 2. Secretary Lynn Jones presides over the voting in of new Board Members

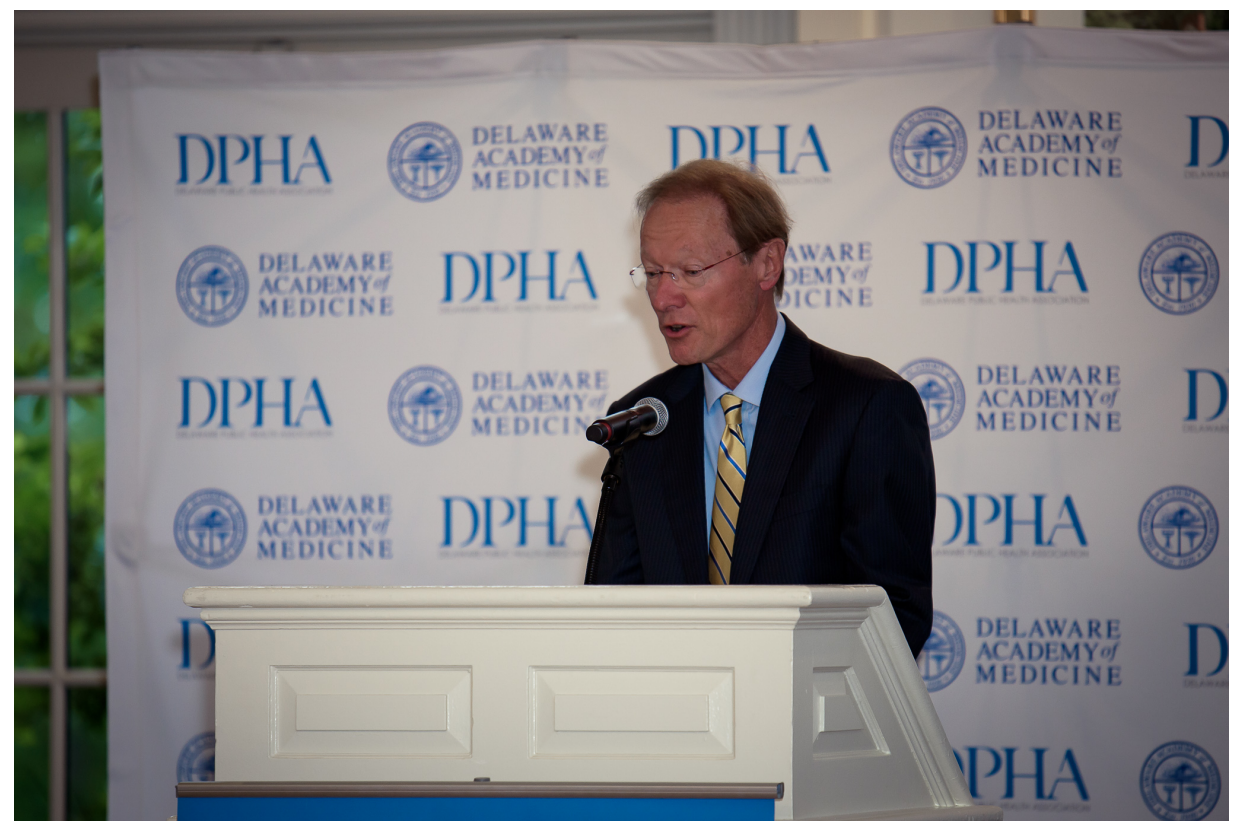

Those new board members include (figures 3-8):

Figure 3. Jeff Cole, DDS - General dentistry practice. Immediate Past President of the American Dental Association. Program Director, General Practice Dentistry Residency, Department of Oral and Maxillofacial Surgery and Hospital Dentistry, ChristianaCare

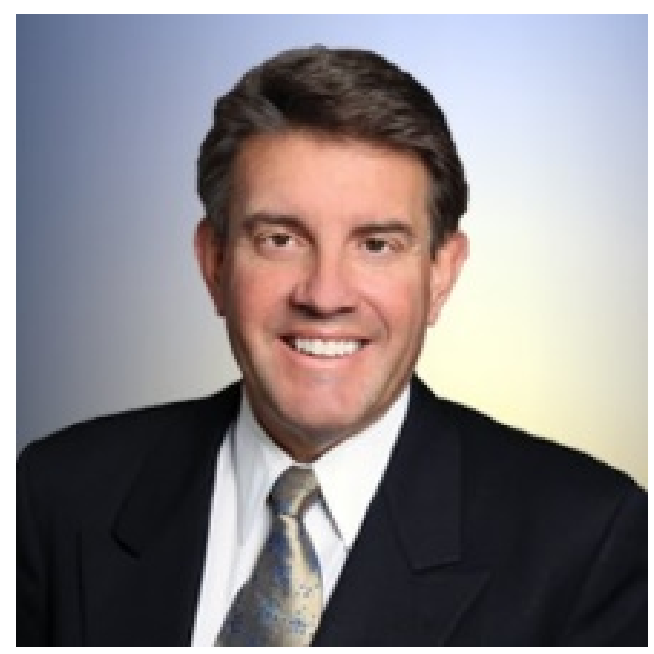

Figure 4. Lee Dresser, MD - Adult Neurologist and a specialist in Sleep Medicine. Affiliated with St. Francis Hospital, Chair of the Delaware Stroke Initiative. 
DOI: $10.32481 / \mathrm{djph} .2021 .07 .015$

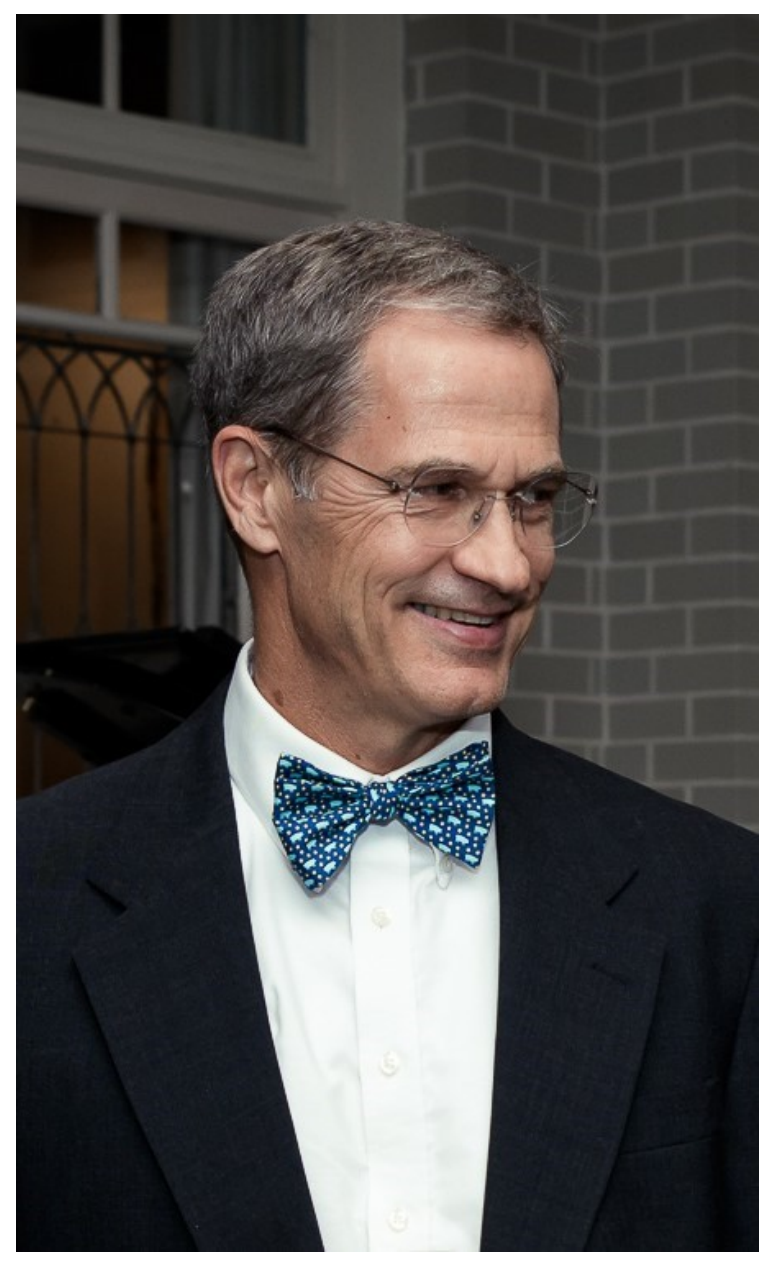

Figure 5. Erin Kavanaugh, MD - Family Physician, Past President of the Delaware Academy of Family Physicians. Clinical Assistant Professor of Family and Community Medicine, Sidney Kimmel Medical College. Program Director, Family Medicine Residency Program, Co-Program Director, Emergency Medicine/Family Medicine Residency Program, ChristianaCare. 
DOI: $10.32481 / \mathrm{djph} .2021 .07 .015$

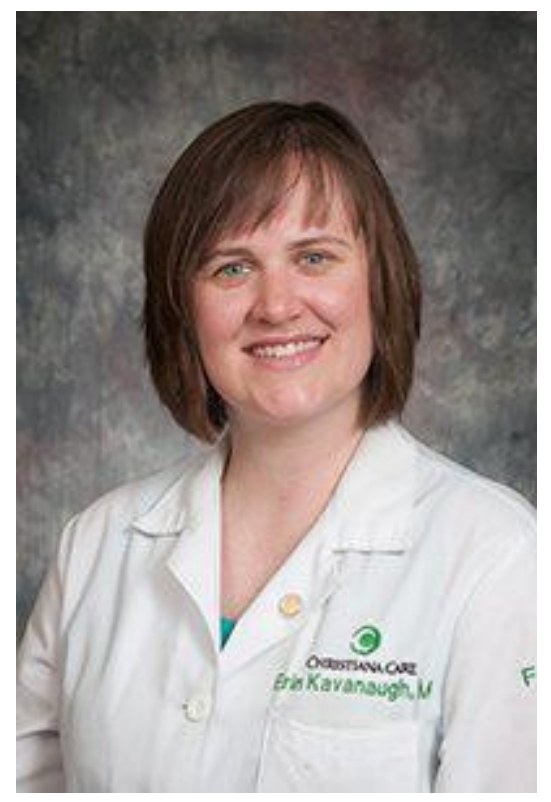

Figure 6. Joe Kelly, DDS - General Dentistry Practice. immediate Past President of the Delaware State Dental Society. Private Practitioner.

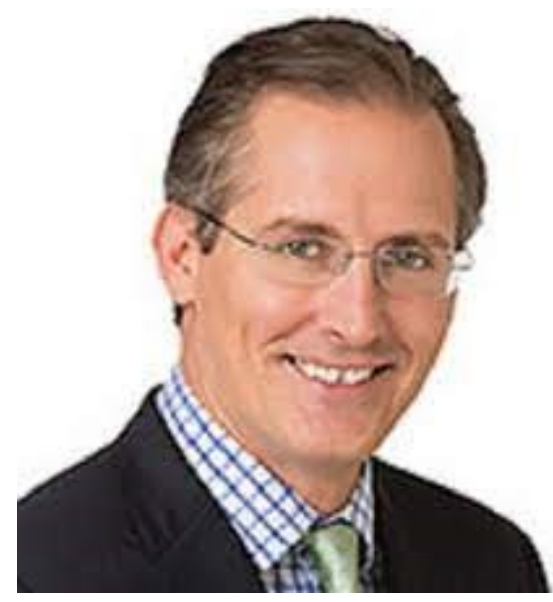

Figure 7. Ann Painter, MSN, RN - Senior Vice President, ChristianaCare Home Health and Community Services. 
DOI: $10.32481 / \mathrm{djph} .2021 .07 .015$

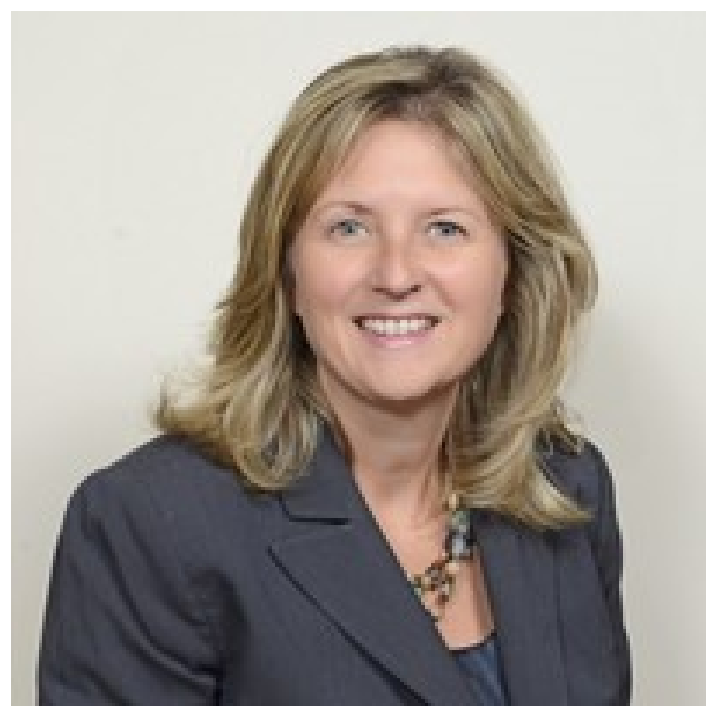

Figure 8. Charmaine Wright, MD, MSHP - Medical Director of the Center for Special Health Care Needs at ChristianaCare, Medical Director of the Mary Campbell Center, and is on the Easterseals of Delaware and Maryland's Eastern Shore Board of Directors

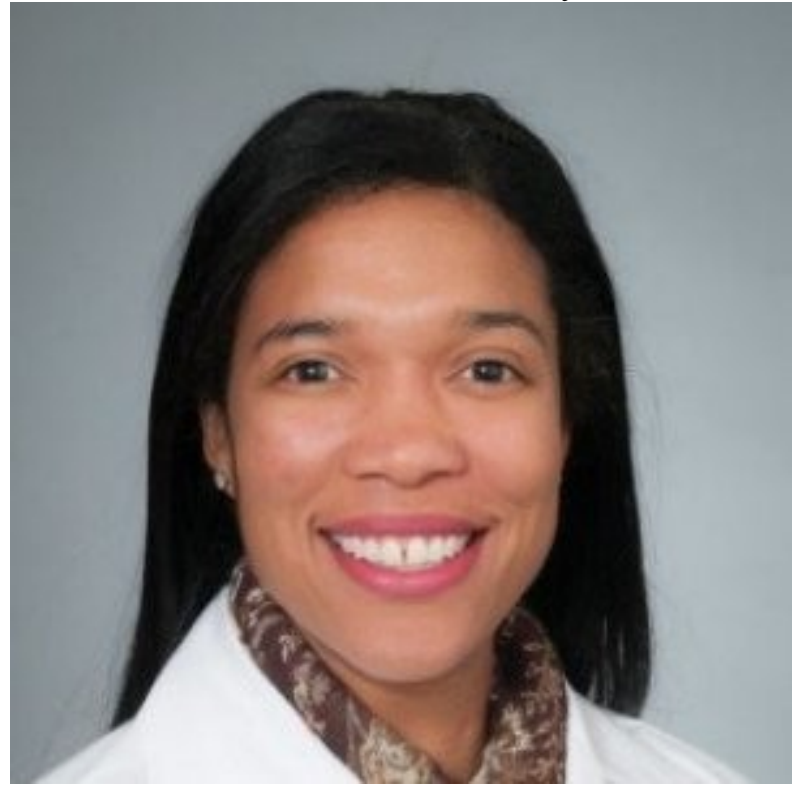

Copyright (c) 2021 Delaware Academy of Medicine / Delaware Public Health Association.

This is an Open Access article distributed under the terms of the Creative Commons Attribution Non-Commercial License (https://creativecommons.org/licenses/by-nc-nd/4.0/) which permits unrestricted non-commercial use, distribution, and reproduction in any medium, provided the original work is properly cited. 